\title{
Enlarged sella of primary childhood hypothyroidism
}

\author{
Paul J. Shogan • Matthew Monson
}

Received: 28 October 2009 /Revised: 5 December 2009/Accepted: 5 January 2010 / Published online: 24 February 2010

(C) Springer-Verlag 2010

A 13-year-old girl presented with growth arrest since the age of 6 years. Lateral radiograph of the skull revealed an enlarged and rounded sella turcica (Fig. 1, arrow). Contrast-enhanced T1 MRI confirmed diffuse enlargement of the anterior pituitary gland resulting in expansion of the sella (Fig. 2, arrow). Laboratory evaluation at presentation revealed a markedly elevated TSH level of $>1,000(0.27-$ $4.20 \mu \mathrm{IU} / \mathrm{mL}$ ) and a low free thyroxine level of 0.046

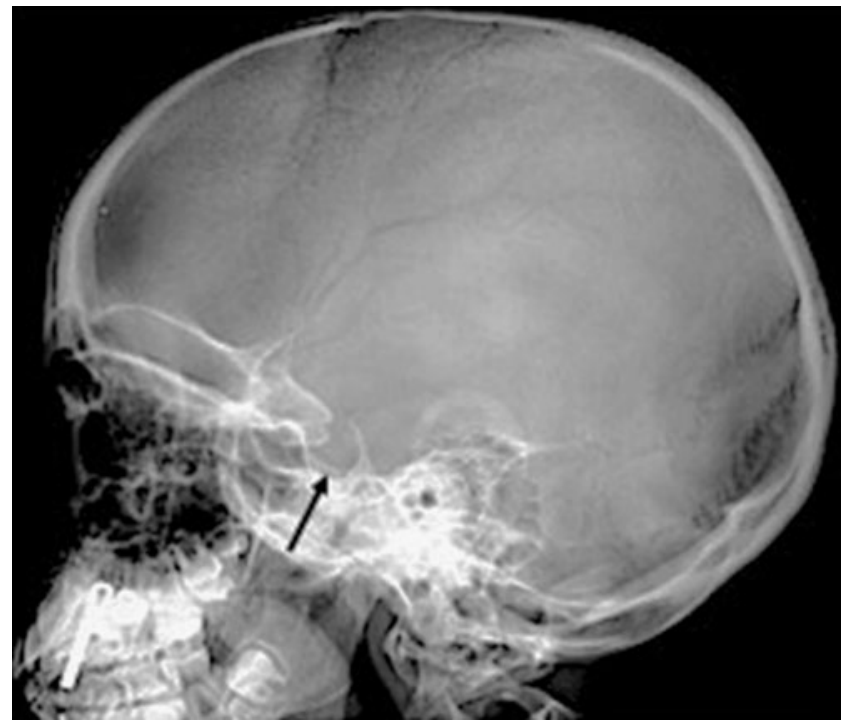

Fig. 1 Lateral radiograph

\begin{abstract}
Military disclaimer The views expressed herein are those of the authors and do not reflect the official policy or position of the Department of the Army, the Department of Defense, nor the U.S. Government.
\end{abstract}

\section{P. J. Shogan · M. Monson $(\bowtie)$}

Department of Radiology, Walter Reed Army Medical Center,

BLDG 2, Rm. 1X, 6900, Georgia Ave. NW,

Washington, DC 20307, USA

e-mail: matthew.monson@amedd.army.mil

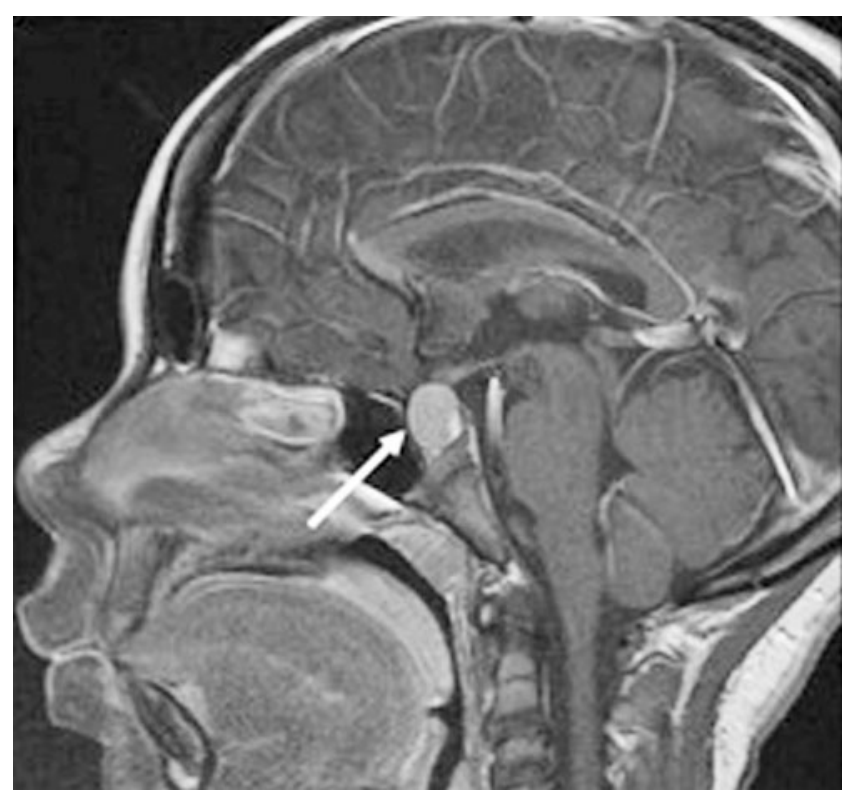

Fig. 2 Sagittal MRI

(1.01-1.79 ng/dL), confirming the diagnosis of primary hypothyroidism.

In an older child with primary hypothyroidism, the large and rounded sella turcica has been described as a "cherry" sella [1]. It results from rebound hypertrophy of the pituitary gland, and is reversible with thyroid hormone replacement therapy $[1,2]$. This case is an excellent example of how the finding of an enlarged sella in a child with growth arrest can aid in the diagnosis of primary hypothyroidism.

\section{References}

1. Swischuk LE, Sarwar M (1977) The sella in childhood hypothyroidism. Pediatr Radiol 6:1-3

2. Osborn AG, Blaser S, Salzman K et al (2004) Diagnostic imaging: brain. Amirsys, Canada, pp 10-12 